\title{
PODER, DISCURSO E PEDAGOGIA: INERÊNCIAS E POSSIBILIDADES NA REAL LUTA EM DEFESA DA ALMA
}

Thiago Luiz Santos de Oliveira * Silene Gelmini Araújo Veloso **

\section{RESUMO}

O objetivo do presente texto é analisar as dimensões do discurso pedagógico no que tange à sua materialização enquanto prática pedagógica. Diante da constatação de que - currículo escolar não é neutro e que, ao contrário, reproduz de uma forma velada, as ideologias que predominam na sociedade se fazem importante o estudo das relações de poder e controle social intrínsecas às dimensões do currículo. A partir desta perspectiva pretende-se refletir acerca do papel da educação no resgate da formação de sujeitos plenos, éticos e cientes do seu papel enquanto agentes sociais.

Palavras-chaves: Prática pedagógica. Poder. Discurso. Currículo. Democracia. Conhecimento. Semiformação.

\section{ABSTRACT}

The purpose of this paper to analyze the dimensions of pedagogical discourse in pedagogical practice. The school curriculum not is neutral, but reproduces the veiled ideologies that prevail in society, is important to study the relations of power and social controls in dimensions of curriculum. From this perspective we intend to reflect about the function of the education in the formation and rescue of full subjects as social agents.

@rquivo Brasileiro de Educação, Belo Horizonte, v. 5, n. 12, set-dez, 2017. 
Keywords: Pedagogical practice. Power. Discourse.

Democracy. Curriculum. Knowledge. Semi-formation.

\section{INTRODUÇÃO}

A discussão acerca do currículo e da escola (como lócus de sua concretização) traz consigo importantes reflexões sobre poder, discurso e pedagogia. Algumas delas estão aqui colocadas no sentido de explicitar as imbricadas e complexas forças presentes na realização de um currículo, que muitas vezes determina a função social da escola que, em última análise, contribui enormemente para a construção da identidade dos sujeitos.

Historicamente, as escolas e os currículos não foram necessariamente criados para ampliar e fortalecer o capital cultural de todas as classes e de todas as comunidades. Mas, ao contrário, para privilegiar conhecimentos, costumes e valores de determinados segmentos mais poderosos da população, contribuindo ideologicamente para a formação da sociedade discriminatória que vivemos até os dias atuais.

O conhecimento selecionado e organizado para veiculação na escola, nunca foi e continua não sendo neutro. É fruto da seleção de conteúdos, princípios e valores que provém de grupos hegemônicos da sociedade. Assim, torna-se importante compreender porque o conhecimento desses grupos é sempre primeiramente representado nas escolas e, que interesses sociais, políticos e ideológicos, ou seja, que critérios orientam a seleção e formatação do currículo. Interesses econômicos e ideológicos incorporaram compromissos com estruturas e políticas educacionais que contribuíram historicamente para a promoção das desigualdades sociais. Daí a importância do papel da escola na manutenção (ou não) de significados:

As escolas não controlam apenas as pessoas; elas também ajudam a controlar significados. Desde que preservam e contribuem o que é considerado como o "conhecimento legítimo" - o conhecimento que "todos devemos ter". - as escolas conferem legitimação cultural ao conhecimento de grupos específicos. Mas isso não é tudo, pois a capacidade de um grupo tornar seu conhecimento em "conhecimento par todos" está relacionada ao poder desse grupo no campo de ação político e econômico mais amplo. Poder e cultura, então, precisam ser vistos, não como entidades estáticas sem conexão entre si, mas como atributos das relações econômicas 
existentes em uma sociedade. Estão dialeticamente entrelaçados, de modo que poder e controle econômico estão interligados com poder e controle cultural. (APPLE, 1982, p.98)

Nesse sentido, é importante contextualizar que a escola precisa ser compreendida através das relações que estabelece com outras instituições da sociedade. Instituições também poderosas econômica, política e socialmente. Essas instituições produzem desigualdades de poder e de acesso a recursos.

É fundamental salientar que as desigualdades podem ser, reforçadas e reproduzidas na escola e pela escola. Através de suas atividades pedagógicas e curriculares, procedimentos de avaliação, o “discurso” por ela veiculado, na formação de docentes ou até mesmo e principalmente através das atividades cotidianas, a escola desempenha um papel importante na manutenção, senão na criação dessas desigualdades.

A temática do papel da escola como certificadora das desigualdades sociais é abordada por Thomas S. Popkewitz em seu livro "Lutando em Defesa da Alma". O autor argumenta sobre o funcionamento da pedagogia nesse cotidiano da escola como uma prática para legitimar os padrões educacionais de "normalidade" e "diferença" na sala de aula.

Através da análise e avaliação do “Teach for América”, um programa alternativo para a formação de professores nos Estados Unidos, Popkewitz (2001) discute como as linguagens de “ajuda” às crianças “diferentes”, utilizadas pelos professores do programa, incorporavam formas de raciocínio sobre elas e sobre o ensino “adequado" a essas crianças. A investigação não tratou de quem atinge o sucesso ou o fracasso ou como o sucesso/fracasso acontecem e sim sobre os sistemas de raciocínio incorporados nas maneiras como ocorre a referência ao sucesso dos "normais" e ao fracasso dos "diferentes".

A educação é produtora de separações que geram um terreno desigual. $E$ as estratégias pedagógicas são construções de diferentes espaços sociais para as crianças. A pedagogia através do currículo, das matérias escolares, avaliação, plano de aula e outros mecanismos, viabilizam o discurso "velado da diferença” e formam o professor e a criança competentes e qualificados para a participação cidadã como também desqualificados para tal. São estratégias da pedagogia “solicitadas” para a transformação

Qrquivo Brasileiro de Educação, Belo Horizonte, v. 5, n. 12, set-dez, 2017. 
das comunidades "desiguais" em "iguais".

Enquanto a história das ciências e as ciências sociais apontam continuamente para as lutas em prol do conhecimento disciplinar como o ponto focal do avanço científico, o local da luta na pedagogia é diferente. É a luta pela alma a ser resgatada. (POPKEWITZ, 2001, p. 112)

No tocante ao conhecimento pode-se utilizar o mesmo raciocínio. O conhecimento se relaciona de forma intrínseca com as relações de poder, sobretudo no que se refere ao controle do "real", ou seja, nas adequações e dinâmicas daquilo que é realidade, e também na validação para que essa mesma realidade seja aceita como verdade enquanto discurso sociopolítico. 0 discurso não é algo axiomático, mas sim socialmente construído. O mesmo raciocínio é valido para o discurso pedagógico. Um exemplo elucidativo acerca da prática discursiva é a escola como instituição. Para alguns a escola representa a maior tradução da construção democrática, para outros é a representação máxima da coerção social, e os seus currículos e práticas instrumentos de controle que legitimam o status quo. É necessário então refletir acerca da legitimação e da validação do discurso pedagógico, principalmente investigando quem este conhecimento representa. 0 discurso possui um caráter dual, sobretudo no que tange a dinâmica do poder. Pode se referir tanto a capacidade de ação efetiva, dentro de uma perspectiva direta e impositiva, como também pode ser considerada uma ação coletiva e cidadã. Dentro dessa perspectiva as massas populares devem ser inseridas na ampliação das ações críticas para uma inserção realmente democrática.

Popkewitz ao deitar seu olhar sobre o Teach For America, sobretudo no que concerne a concretude de sua ação pedagógica percebe que práticas que qualificam e desqualificam os educandos em termos sociais são patentes. Para o autor a distinção entre urbanidade e ruralidade só se aplica em âmbito geográfico. Apesar das diferenciações físicas o discurso pedagógico em sua realidade prática não apresenta grandes distinções, ou seja, é socialmente combinado. Percebe-se que a construção linguística da urbanidade e da ruralidade apesar de se constituir como uma oposição geográfica é pautada em sua construção teórica pelos mesmos sistemas e idéias pedagógicas. Percebe-se então uma homogeneização do discurso pedagógico, onde muitas vezes o respeito ao diferente se torna instrumento retórico.

Qrquivo Brasileiro de Educação, Belo Horizonte, v. 5, n. 12, set-dez, 2017. 
Não havia discursos pedagógicos distintos que distinguissem as práticas de ensino urbanas das rurais quando se tratava das características da aprendizagem, das realizações ou das características pedagógicas das crianças. Os mesmos sistemas de idéias pedagógicas circulavam nas diferentes localizações geográficas. Por essa razão, uso as duas palavras como uma - urbano/rural. (POPKEWITZ, 2001, p. 11)

O conhecimento presente no currículo tem papel fundamental na "luta pela alma". O currículo envolve o que Popkewitz denominou “alquimia”.

[...] as qualidades socialmente construídas da ciência, da ciência social, da história e da literatura são criadas para parecerem uma série de entidades lógicas ou objetos da lógica. Em várias matérias escolares, supõe-se que o conhecimento disciplinar deva assumir a forma de uma série de estruturas lógicas e naturais que funcionem como bases para que a aprendizagem ocorra. Os conceitos, as generalizações e os princípios das matérias escolares são tratados como objetos lógicos e analíticos a serem aprendidos. (POPKEWITZ, 2001, p. 112)

Essa concepção do conhecimento e do currículo como objetos da lógica supõe que os conteúdos curriculares são dissociados dos indivíduos que têm apenas a função de compreendê-los e afasta a idéia do sujeito na construção desse conhecimento. Esse tratamento dado às matérias escolares de forma fixa e inflexível permite um deslocamento da pedagogia para as subjetividades das crianças que devem ser "salvas". Assim, as crianças que têm as disposições certas conseguem aprender e, assim, obtêm a "redenção”, "integridade” através dos seus sucessos, enquanto aquelas que não possuem tais qualidades estão perdidas.

O livro didático aparece como mais um instrumento da concretização de um currículo que deve ser assimilado por todos. O livro transforma-se no próprio instrumento de transmissão do currículo. Porém, o que ocorre é que via livro didático transmite-se um currículo fragmentado tanto em termos da divisão das matérias escolares quanto dos próprios textos de uma mesma matéria que aparecem “pinçados” de suas fontes. É a distribuição dos “fragmentos de conhecimento".

É importante compreender então que as controvérsias sobre conhecimento oficial, que usualmente se centram no que é incluído ou excluído dos livros didáticos, significam relações e histórias políticas, econômicas e culturais

Qrquivo Brasileiro de Educação, Belo Horizonte, v. 5, n. 12, set-dez, 2017. 
muito mais profundas. (APPLE, 1997, p. 77)

$\mathrm{Na}$ realidade os livros didáticos enquanto reprodutores do conhecimento oficial incorporam uma tradição seletiva, ou seja, privilegia a visão de um determinado grupo social, desconsiderando outros. O livro didático de certa forma é uma forma eficiente de informar as gerações futuras sobre as formas ideológicas de uma determinada sociedade. É importante salientar que o livro didático enquanto símbolo e representação social e cultural, não é a expressão de todo corpo social, mas sim a visão de um grupo específico. O livro didático se insere em um campo de disputas políticas e econômica, portanto passível as inerências mercadológicas. O controle, a coerção social, e a dominação cultural estão presentes desde a escolha dos eixos curriculares e conteúdos até as demandas de impressão e distribuição.

A inserção das minorias nos debates acerca do currículo e da construção do livro didático tem alterado o panorama da organização e disseminação do conhecimento. Vários grupos lutam para que suas perspectivas e olhares sejam introduzidos na dinâmica da legitimação do conhecimento, sobretudo nos livros e textos didáticos. Obviamente a inserção dessas mesmas minorias perpassa apenas a simples menção, o que de fato só confirma o processo de dominação, a inserção real só irá ocorrer através da participação desses grupos minoritários na construção e formulação de materiais pedagógicos.

Ainda assim, esse conhecimento não chega a todos da mesma maneira visto que a alguns, faltam conhecimentos anteriores, os "pré-requisitos". É o caso dos "diferentes" cuja formação (cultura familiar, hábitos, ou até mesmo material de leitura) é deficiente. Deficiente, claro, em relação à classe hegemônica que dita qual é a cultura, quais são os conhecimentos e os hábitos a serem assimilados pela sociedade.

Outro instrumento importante na manutenção da racionalidade do processo de ensino refere-se ao plano de aula que determina a sequência, o ritmo e a organização das práticas de ensino. Tal recurso apresenta-se como uma tecnologia normalizadora.

É uma maneira de organizar o que o professor quer, faz e alcança. Ele determina os objetivos de uma aula, estabelece uma sequência de instrução que conduz ao cumprimento dos objetivos e depois acrescenta algum esquema de avaliação para estabelecer o grau de sucesso alcançado no exercício do ensino. (POPKEWITZ, 2001, p.91)

@rquivo Brasileiro de Educação, Belo Horizonte, v. 5, n. 12, set-dez, 2017. 
O próprio capitalismo cria um sistema de dominação e normalização que neutraliza a capacidade de critica e reflexão do indivíduo. Esses artifícios de dominação são intrínsecos ao sistema, portanto de difícil rejeição. Para Adorno a crítica é dotada de um caráter histórico, de inserção e capacitação do homem de pensar o mundo a partir das suas demandas enquanto indivíduo. A sociedade contemporânea, a sociedade do capitalismo administrado se caracteriza pela padronização cultural, onde a venda de bens culturais se torna um mecanismo de controle social.

Dessa forma, a educação seria condição básica para a luta contra a massificação e a alienação, promovendo a formação de indivíduos plenos. A prática educacional, ao combater o processo de exclusão, combate também o processo de semiformação do sujeito, e a lógica da massificação que muitas vezes se impõe pelo próprio discurso pedagógico. Na sociedade de massas a reprodução da vida principalmente no que tange as suas condições materiais e imateriais são dotadas de um caráter totalizante. Dessa maneira na formação social capitalista percebe-se certo determinismo no que se refere às opções do sujeito. 0 que de fato parece escolha é algo determinado previamente e concebido peal Indústria Cultural. As massas são semiformadas à medida que não constroem reflexões acerca de suas escolhas, mas sim reproduzem como cópia as afirmações e modelos já vigentes.

Para o cientista social alemão Theodor Adorno a semiformação é fruto de um complexo enlace das relações sociais, econômicas e políticas dominantes. É a sujeição a aquilo que se adere, àquilo que é socialmente determinado de forma não reflexiva e determinante. Para romper com esta lógica determinista faz-se necessário perceber as condições objetivas determinantes em meio aquilo que é subjetivo, assim percebendo o que é a dialética da produção, intervindo na realidade histórica. 0 processo dialético é congelado o que é gera uma sociedade semiformada, em que os sujeitos não reagem criticamente às situações da realidade, pautando muitas vezes sua existência pelo outro. A superação dessa condição só seria possível pela negação, pela crítica. A reflexão possibilitaria a emancipação do sujeito, a superação das determinações objetivas. A prática educativa tem o explicito papel de levar os homens a perceber as contradições da sociedade em que vivem. A educação deve ser reflexiva e emancipadora, mas esta emancipação deve ser pautada na crítica da realidade e dos condicionantes objetivos da

Qrquivo Brasileiro de Educação, Belo Horizonte, v. 5, n. 12, set-dez, 2017. 
sociedade.

O mundo dos homens é organizado de determinada maneira e é preciso decifrar as condições e os condicionantes que causam seu modo determinado de ser. A emancipação como conscientização é a reflexão racional pela qual o que parece natural, essencial na sociedade cultural, decifra-se como ordem socialmente determinada em dadas condições da produção real efetiva da sociedade. (MAAR, 2003, p.14)

Para Popkewitz lutar em defesa da alma, sobretudo é resgatar o real papel da prática educativa. E qual seria este papel? Formar sujeitos plenos cientes de seus direitos e deveres, prontos para intervirem de forma ética em uma sociedade democrática. A “alma” então seria o próprio sentido de se educar. Dentro dessa perspectiva de se defender a "alma” na prática pedagógica na formação do sujeito, o currículo deve ser pensado e tratado como uma via dialética entre os entes do processo de escolarização, sobretudo escola e aluno. Deve ser estabelecida uma relação de mutualidade, na construção daquilo que de fato deve representar o currículo. Os saberes escolares representam, sobretudo em seu processo de seleção, uma gama de relações hierarquizadas de estratificação, que em suma denotam as relações de poder implícitas e explicitas na formatação do currículo. É necessário que a prática pedagógica e a construção do currículo se alicercem em princípios democráticos, de escolha e participação 0 discurso pedagógico não pode ser uma mera realidade retórica, mas sim calcado em bases efetivas das demandas e necessidade dos sujeitos a quem esse mesmo discurso possui incidência. Propõe-se uma interlocução entre a teoria e a evidência, ou seja, a prática discursiva e a realidade.

Segundo Popkewitz o discurso pedagógico continua separando os educandos em compartimentos estanques, mediante suas habilidades e níveis de conhecimento. Esses discursos muitas vezes não consideram de fato o esforço e a mobilização da criança, uma vez que os parâmetros que definem questões como a subjetividade não é contemplada neste mesmo discurso. A mudança da pratica pedagógica passa pela mudança do discurso pedagógico. É necessário refletir acerca da política do espaço da pedagogia no tocante a prática discursiva e sua materialização na sala de aula. Para isso é necessário um currículo socialmente construído onde os indivíduos são responsáveis por dotar as práticas sociais de sentidos e significações. O mundo social se traduz então na interação dialética

Qrquivo Brasileiro de Educação, Belo Horizonte, v. 5, n. 12, set-dez, 2017. 
entre os significados produzidos pelos indivíduos.

Um currículo crítico não aceita o enquadramento e a normatização existente na seleção do que deve ser ensinado. Procura-se então afirmar uma educação ampliada que valorize as várias formas de interação e organização social, ao invés do mero enquadramento. 0 enquadramento, a delimitação não somente dos conteúdos, mas também o cerceamento das atitudes dos educandos e também dos professores refletem as relações de poder existentes no âmago do processo educativo.

Uma prática educativa crítica e um discurso pedagógico interacionista devem levar em consideração várias significações sociais e representações culturais, uma vez que os currículos quando socialmente construídos e historicamente forjados se tornam expressões de cidadania.

Nesse sentido, a real "Luta em defesa da ALMA" deve significar a instrumentalização do sujeito no sentido de sua inserção política, social e cultural de forma participativa e construtiva. Uma verdadeira inserção não pode ser pensada no sentido da assimilação de culturas sobrepostas. Se assim for estará novamente colocada a questão do poder de uns sobre outros.

A escola, como uma das instituições formadoras de indivíduos e de sujeitos precisa assumir o seu papel indelegável: formação, educação e ensino.

\section{REFERÊNCIAS}

ADORNO, Theodor; HORKHEIMER, Max. A indústria cultural: o esclarecimento como mistificação das massas. In: ADORNO, Theodor. A dialética do esclarecimento. Rio de Janeiro, Zahar Editora, 1969.

APPLE, Michael W. Conhecimento oficial: a educação democrática numa era conservadora. Petrópolis: Vozes, 1997. 267p.

APPLE, Michael W. Ideologia e currículo. São Paulo: Brasiliense, 1982. 246p.

BERNSTEIN, Basil B. A estruturação do discurso pedagógico: classe, códigos e controle. Petrópolis: Vozes, 1996. 307p.

BOURDIEU, Pierre A. Escola conservadora e as desigualdades frente à escola e à cultura. In: CATANI, A.(Org). Escritos de Educação. Petrópolis: Vozes, 1998.

FORQUIN, Jean-Claude. Escola e cultura: as bases sociais e epistemológicas do

@rquivo Brasileiro de Educação, Belo Horizonte, v. 5, n. 12, set-dez, 2017. 
conhecimento escolar. Porto Alegre: Artes Medicas, 1993. 205p.

FOURQIN, Jean Claude. Saberes escolares, imperativos didáticos e dinâmicas sociais. In: Teoria e Educação, v.5, 1992.

GOODSON, Ivor. Etimologias, epistemologias e o emergir do currículo. In: GOODSON, Ivor. Currículo, teoria e história. Petrópolis Vozes. 1995. Cap. 2.

MAAR, Wolfgang. Adorno, semiformação e educação. Educação e Sociedade, Campinas, v.24, n.83, 2003.

POPKEWITZ, Thomas S. Lutando em defesa da alma: a política do ensino e a construção do professor. Porto Alegre: Artmed, 2001. 158p. 